\section{Neuropathic ocular pain: an important yet underevaluated feature of dry eye}

\begin{abstract}
Dry eye has gained recognition as a public health problem given its prevalence, morbidity, and cost implications. Dry eye can have a variety of symptoms including blurred vision, irritation, and ocular pain. Within dry eyeassociated ocular pain, some patients report transient pain whereas others complain of chronic pain. In this review, we will summarize the evidence that chronicity is more likely to occur in patients with dysfunction in their ocular sensory apparatus (ie, neuropathic ocular pain). Clinical evidence of dysfunction includes the presence of spontaneous dysesthesias, allodynia, hyperalgesia, and corneal nerve morphologic and functional abnormalities. Both peripheral and central sensitizations likely play a role in generating the noted clinical characteristics. We will further discuss how evaluating for neuropathic ocular pain may affect the treatment of dry eye-associated chronic pain.

Eye (2015) 29, 301-312; doi:10.1038/eye.2014.263;

published online 7 November 2014
\end{abstract}

\section{Introduction}

Per the Definition and Classification Subcommittee of the International Dry Eye WorkShop (DEWS), dry eye is 'a multifactorial disease of the tears and ocular surface that results in symptoms of discomfort, visual disturbance, and tear film instability with potential damage to the ocular surface. It is accompanied by increased osmolarity of the tear film and inflammation of the ocular surface. ${ }^{\prime 1}$ Beyond the eye, the disorder also involves the Lacrimal Functional Unit, ${ }^{2}$ consisting of the ocular surface, the main lacrimal gland, and the interconnecting innervation.

Population-based studies in various US cities have utilized questionnaires (different questionnaires for different studies) to evaluate the frequency of dry eye, with an estimated prevalence of $\sim 15 \%$. $^{3-7}$ Similar studies
A Galor ${ }^{1,2}$, RC Levitt ${ }^{1,3,4,5}$, ER Felix ${ }^{1,6}$, ER Martin ${ }^{4,5}$ and CD Sarantopoulos 1,3

(2)

conducted in several countries around the world including Germany, ${ }^{8}$ Australia,, 10 Japan, ${ }^{11-14}$ India, ${ }^{15}$ Thailand, ${ }^{16}$ and Indonesia ${ }^{17}$ have resulted in similar prevalence estimates. As summarized in the DEWS report, the prevalence of dry eye is most likely in the range of $5-30 \%$ of the population aged $\geq 50$ years. ${ }^{18}$ Dry eye complaints are dominated by various symptoms including blurred vision, irritation, and pain (eg, burning, aching); collectively causing great morbidity. Symptoms associated with dry eye are a leading cause of visits to optometry and ophthalmology clinics and its treatment has significant cost implications. ${ }^{19,20}$ Dry eye adversely affects quality of life as its symptoms interfere with daily activities such as driving, working, reading, and watching television. ${ }^{21}$ In a similar manner, studies using the Impact of Dry Eye on Everyday Life (IDEEL) questionnaire have found that dry eye negatively affects social, physical, and mental functioning. ${ }^{22,23}$

Currently, clinicians split dry eye into two main categories: aqueous deficiency and evaporative, as reviewed in the Definition and Classification DEWS report. ${ }^{1}$ Dry eye treatments are generally geared toward improving these tear film components based on a long-standing paradigm that tear dysfunction underlies dry eye symptoms. Aqueous deficiency is typically addressed with tear replacement therapy and punctal occlusion, whereas evaporative dry eye is managed with lid hygiene and topical and/or oral antibiotics (used for nonantibiotic properties such as their anti-inflammatory effects ${ }^{24}$ ). In common to both, anti-inflammatory agents are often used (for varying durations) to treat the inflammatory component of dry eye.

Although several studies have reviewed that neurosensory dysfunction can be a component of dry eye symptoms in some patients, ${ }^{25,26}$ this aspect of dry eye is not routinely tested for (or treated) in the clinical setting. A better
${ }^{1}$ Miami Veterans

Administration Medical Center, Miami, FL, USA

${ }^{2}$ Bascom Palmer Eye Institute, University of Miami, Miami, FL, USA

${ }^{3}$ Department of Anesthesiology, Perioperative Medicine and Pain Management, University of Miami Miller School of Medicine, Miami, FL, USA

${ }^{4}$ John P Hussman Institute for Human Genomics, University of Miami Miller School of Medicine, Miami, FL, USA

${ }^{5} J o h n$ T Macdonald Foundation Department of Human Genetics, University of Miami Miller School of Medicine, Miami, FL, USA

${ }^{6}$ Department of Physical Medicine and Rehabilitation, University of Miami Miller School of Medicine, Miami, $\mathrm{FL}$, USA

Correspondence: A Galor, Bascom Palmer Eye Institute, University of Miami, 900 NW 17th Street, Miami, FL 33136, USA Tel: +1 305326 6000; Fax: +1 3055753312

E-mail: agalor@

med.miami.edu

Received: 25 March 2014 Accepted in revised form: 6 September 2014 Published online:

7 November 2014 
understanding of the neuropathophysiology underlying dry eye pain will facilitate the development of novel therapies that can target these mechanisms. This review will summarize research findings on neurosensory dysfunction in dry eye and discuss how they may affect the diagnosis and treatment of dry eye pain.

\section{Methods}

A PubMed search was conducted using the terms 'dry eye' AND 'nociceptive pain', 'neuropathic pain', 'sensitivity', 'hyperalgesia', 'allodynia', 'aesthesiometer', 'esthesiometer', 'quantitative sensory testing', 'environment', 'transient receptor potential (TRP)', 'neuropeptides', and 'genetics'. All searches were limited to the English language. Articles were excluded if they studied ocular pain associated with trigeminal neuralgia, contact lens use, or acute injury (eg, refractive surgeryrelated dry eye). All eligible articles were reviewed and summarized.

\section{Dry eye as a pain disorder}

Pain, as defined by the International Association for the Study of Pain (IASP), is 'an unpleasant sensory and emotional experience associated with actual or potential tissue damage, or described in terms of such damage' ${ }^{27}$ Based on this definition, some patients with dry eye (depending on their symptoms) have pain. Within the group with pain, some patients have transient pain, whereas others have persistent symptoms and a more chronic disease course (typically defined as symptom duration of $>3-6$ months).

Pain disorders are broadly grouped into two categories: nociceptive pain and neuropathic pain, and both may be involved in dry eye. Nociceptive pain is usually transient and a result of tissue damage and inflammation. ${ }^{28}$ In the case of dry eye, various insults may lead to ocular surface damage including infection, inflammation, trauma, adverse environmental conditions, abnormal ocular anatomy, and high tear osmolarity. Neuropathic pain is defined as 'pain arising as direct consequence of a lesion or disease affecting the somatosensory system' and is more likely to be chronic. ${ }^{29}$ In dry eye, the inciting factors for nociceptive and neuropathic pain may be the same but the difference is that these stimuli can lead to transient or persistent changes in the phenotype of sensory neurons. ${ }^{28}$

\section{The ocular sensory apparatus: primary nociceptors and secondary and tertiary neurons}

The cornea is innervated by branches of the nasociliary nerve, a branch of V1 (ophthalmic division of the trigeminal nerve). Nerve bundles enter the peripheral cornea in a radial manner and lose their myelin sheath $\sim 1 \mathrm{~mm}$ from the limbus. ${ }^{30}$ The nerves continue to branch and eventually turn 90 degrees and proceed to the corneal surface. ${ }^{30,31}$ The unique location of the free corneal nerve endings between the cells of the superficial epithelium, very near to the ocular surface, places them in a vulnerable position to repeated damage from environmental exposures (evaporation, pollution, and so on). ${ }^{26}$

As reviewed by Rosenthal and Borsook, ${ }^{26}$ different types of nociceptor (pain) fibers are found within the cornea including mechanoreceptors ( $\sim 20 \%$ of total sensory population), polymodal receptors $(\sim 70 \%$ of total sensory population), and cold receptors ( $\sim 10 \%$ of total sensory population). As reviewed by Belmonte and Gallar, $^{32}$ mechanoreceptors are the fastest conducting nociceptors whose peripheral endings are activated by mechanical forces. They are responsible for the sharp pain, experienced when an object touches the cornea or conjunctivae. Polymodal nociceptors are activated by mechanical forces, but also by other stimuli like heat, acidic/basic conditions, and chemicals. Cold thermoreceptors are the most recently described fibers responding to a reduction in temperature (eg, evaporative cooling, cold). ${ }^{32,33}$

Transient receptor protein (TRP) channels are found in the terminal cell membranes of nociceptors and are responsible for detecting these various stimuli. For example, TRPV1 channels detect a variety of noxious stimuli including abnormal $\mathrm{pH}$, heat, and chemicals. ${ }^{34}$ TRPM8, on the other hand, detects small temperature drops on the ocular surface and is thus able to sense evaporative changes in the tear film. ${ }^{35}$ In this manner, this channel is believed to be involved in regulating basal tearing. In mice lacking TRPM8 channels, cold thermoreceptors did not fire spontaneously and did not increase their firing rate with temperature drops. These mice had abnormally low basal tearing but normal tearing in response to other noxious stimuli. A similar correlate was found in healthy volunteers who displayed decreased tearing at $43^{\circ} \mathrm{C}$ compared with 18 and $25^{\circ} \mathrm{C}$ $(n=11)^{35}$

Corneal nociceptors have their primary cell bodies in the trigeminal ganglion and first synapse in the trigeminal subnucleus interpolaris/subnucleus caudalis (Vi/Vc) transition zone, and in the subnucleus caudalis / upper cervical transition zone $\left(\mathrm{Vc} / \mathrm{C}_{1-2}\right)$ (Figure 1). ${ }^{36,37}$ From the spinal trigeminal nuclear complex, secondorder axons decussate and join the contralateral spinothalamic pathways and synapse in the thalamus. Third-order neurons then relay information to the supraspinal centers, including the somatosensory cortex. Perception of pain is also simultaneously modified by 


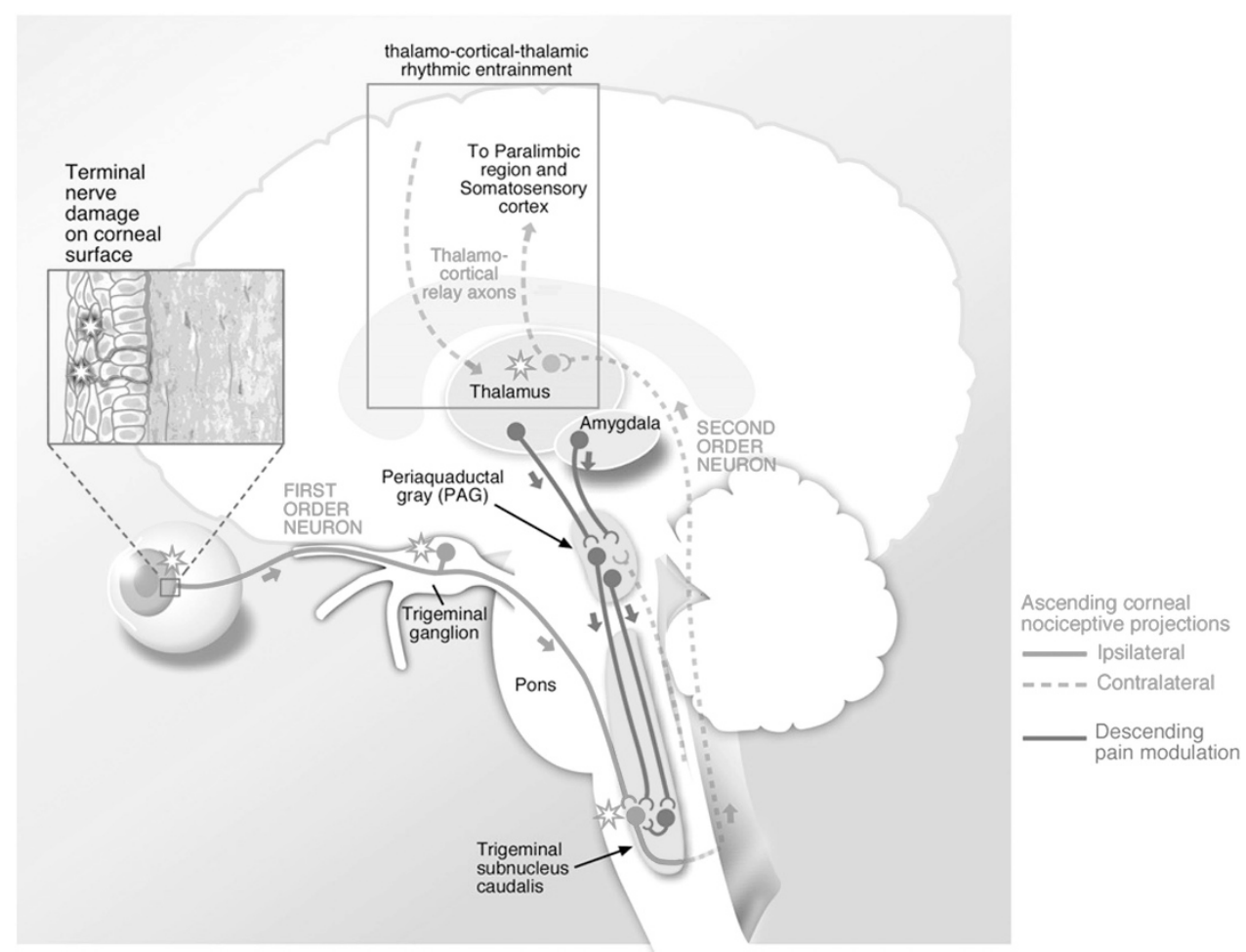

Figure 1 A simplified version of the ocular sensory pathway. First-order neuron (solid line) with nerve ending in the cornea, cell body in the trigeminal ganglion, and synapse in the subnucleus caudalis. In actuality, however, there are multiple synapses for each nociceptor in the trigeminal subnucleus interpolaris/subnucleus caudalis (Vi/Vc) transition zone, and in the subnucleus caudalis/ upper cervical transition zone $\left(\mathrm{Vc}_{\mathrm{c}} / \mathrm{C}_{1-2}\right)$. Second-order neurons (dashed line) decussate and join the contralateral spinothalamic pathways and synapse in the thalamus. Third-order neurons (dashed line) then relay information to the supraspinal centers, including the somatosensory cortex. Reproduced with permission from Rosenthal and Borsook. ${ }^{26}$

descending pain pathways. ${ }^{28}$ Signals are transmitted from the limbic system and midbrain through the periaqueductal grey to the brainstem, where signals are modulated, and then continue back to the trigeminal subnucleus caudalis.

The above schema is an undoubtedly simplified version of the ocular sensory apparatus. For example, dry eye patients report a variety of ocular complaints when describing their symptoms including burning, aching, dryness, grittiness, irritation, and itch. It is likely that different sensations are transmitted through slightly different pathways. For example, in rats subjected to ultraviolet irradiation-induced photokeratitis, hypertonic saline-evoked activity of ocular neurons in the $\mathrm{Vc}_{\mathrm{c}} / \mathrm{C}_{1}$ junction was enhanced after 2 days, but a similar correlate was not seen in the $\mathrm{Vi} / \mathrm{Vc}_{\mathrm{c}}$ transition region. ${ }^{38}$ This suggests that the $\mathrm{Vc}_{\mathrm{c}} / \mathrm{C}_{1}$ region is important in pain sensation. In contrast, drying of the ocular surface affected neurons in the $\mathrm{Vi} / \mathrm{Vc}$ transition as opposed to the $\mathrm{Vc}_{\mathrm{c}} / \mathrm{C}_{1}$ junction. ${ }^{39}$ In a similar manner, the ocular sensation of itch has been postulated to also go through the $\mathrm{Vi} / \mathrm{Vc}_{\mathrm{c}}$ junction, as reviewed by Stapleton et al. ${ }^{34}$
In addition, sensory nerves also innervate the conjunctiva and eyelid margins and these nerves also likely play a role in dry eye-associated ocular pain. However, less information is available on their morphology and functions. ${ }^{34}$

\section{Environmental conditions, inflammation, and their effect on peripheral corneal nerves}

\section{Environmental conditions}

Many environmental conditions can activate corneal nociceptors and thereby produce dry eye symptoms. Experimentally, the controlled adverse environment (CAE) model has been used both as a screening tool to identify patients susceptible to environmental insults and as a diagnostic tool to test various dry eye therapeutics. ${ }^{40}$ For example, 19 dry eye patients and 20 controls were exposed to low humidity for $2 \mathrm{~h}$ in the CAE. After exposure, both dry eye patients and controls had significant ocular surface alterations including increased corneal staining, decreased TBUT, and increased matrix 
metalloproteinase-9 (MMP-9) tear levels. ${ }^{41}$ In another study by the same group, similar findings were seen after 20 dry eye patients were exposed to a CAE simulating an in-flight airplane cabin for $2 \mathrm{~h} .{ }^{42}$ Environmental factors such as high altitude, ${ }^{43}$ wind, ${ }^{15}$ air pollution, ${ }^{15,44}$ volcanic eruption, ${ }^{45}$ dust, $^{46}$ and chemicals ${ }^{47,48}$ have also been associated with transient and/or chronic dry eye. In our study of 3.41 million patients seen in 394 Veteran Affairs (VA) eye clinics within the continental United States, we found that several environmental factors were significantly associated with the risk of a dry eye diagnosis. ${ }^{49}$ Among these, air pollution and atmospheric pressure emerged as the most significant predictors. For example, veterans in Chicago and New York City were three to four times more likely to be diagnosed with dry eye as compared with less urban areas with relatively low concentrations of aerosol optical depth (a surrogate marker of air pollution) such as Ukiah (CA, USA).

\section{Inflammation}

Adverse environmental conditions and local abnormalities, such as eyelid malposition, may lead to ocular surface damage. This damage to epithelial cells and nociceptors can lead to the release of various inflammatory mediators, such as adenosine triphosphate, prostaglandins (PGs), and substance $\mathrm{P}$, and cause immune cell infiltration (Figure 2). ${ }^{28}$ In fact, elevated levels of $\mathrm{PGE}_{2}$ have been found in the tears of dry eye patients as compared with controls. ${ }^{50}$ Similarly, mice subjected to adverse environmental conditions also displayed higher cyclooxygenase 2 (COX2) and PGE synthase mRNA levels on the ocular surface. ${ }^{50}$ In line with immune cell recruitment, $\mathrm{T}$ cells have been found in the conjunctivae ${ }^{51}$ and elevated levels of inflammatory cytokines have been found in the tears of dry eye patients. ${ }^{52,53}$ Specifically, tear levels of IL-2, IL-4, IL-5, IL-6, IL-8, IL-10, IL-17, and tumor necrosis factor- $\alpha$ (TNF- $\alpha$ ) have been found to be elevated in dry eye compared with control subjects. ${ }^{52,53}$ Environmental stress can also lead to an increase in reactive oxygen species. For example, oxidative stress-induced lipid peroxidation was increased on the conjunctivae of Sjogren's patients as assessed by detection of hexanoyl-lysine (HEL) and 4-hydroxy-2-nonenal (4HNE) protein adducts. ${ }^{54}$

Furthermore, corneal epithelial damage may upregulate nerve growth factor (NGF) and decrease calcitonin generelated peptide (CGRP) levels. ${ }^{55-57}$ Finally, MMP-9 levels have been shown to increase in the tears of dry eye patients. ${ }^{58,59}$ In addition to pro-inflammatory mediators, there are anti-inflammatory mediators, such as those derived from omega 3 and 6 fatty acids (ie, resolvins and

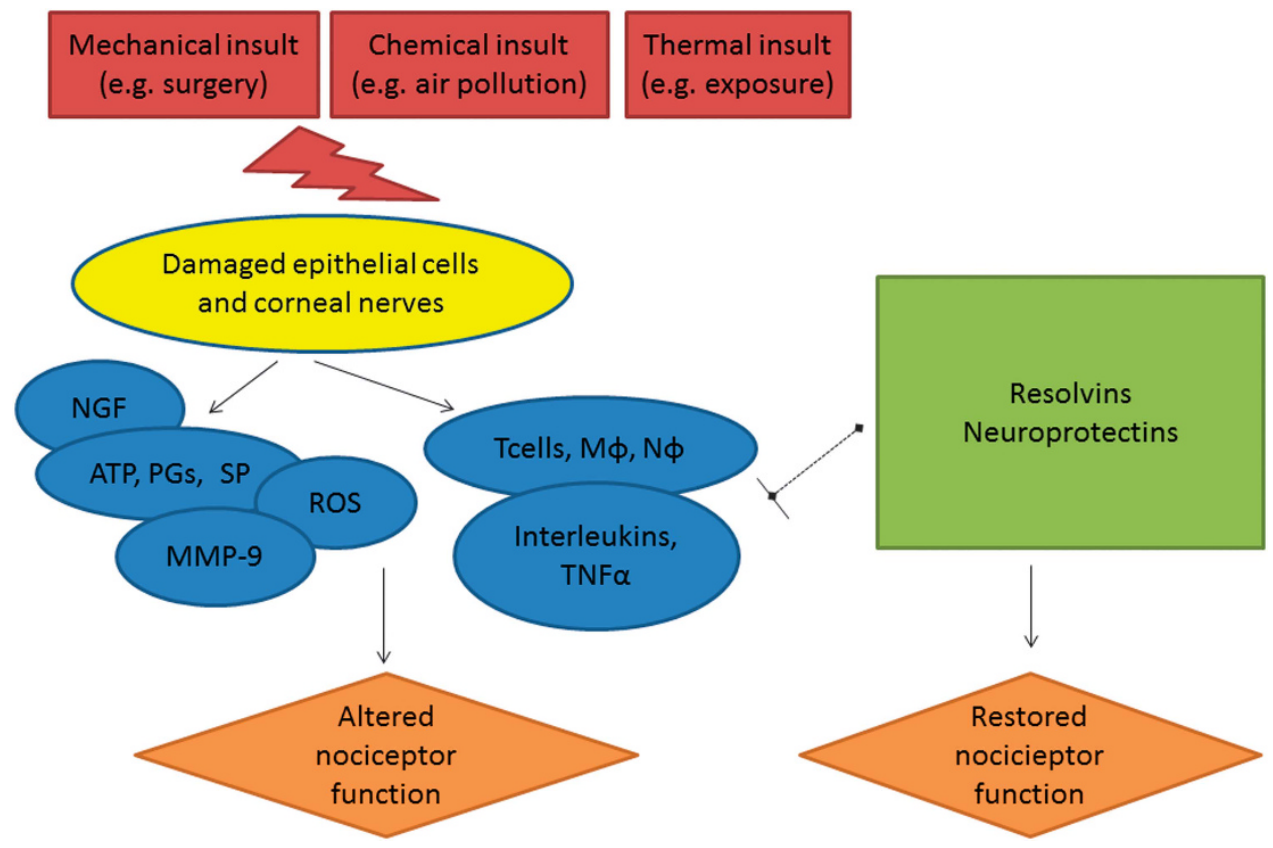

Figure 2 A simplified version of the relationship between environmental insults, inflammation, and nociceptor function. Mechanical, chemical, and thermal insults can damage corneal epithelial cells and nociceptors that results in a cascade of inflammatory mediators including adenosine triphosphate (ATP), prostaglandins (PGs), substance P (SP), matrix metalloproteinases (MMPs), reactive oxygen species (ROS), and nerve growth factor (NGF). In addition, there is an influx of immune cells including T cells, macrophages (M $\phi)$, and neutrophils $(\mathrm{N} \phi)$. These cells secrete a variety of cytokines (interleukins and tumor necrosis factor (TNF)) that all alter the function of nociceptors. Other mediators, including resolvins and protectins, are involved in ending the inflammatory cascade and restoring nociceptor function. Persistent environmental stress or inflammatory responses can lead to permanent changes in nociceptor function. 
protectins ${ }^{60}$ ), and the presence of both pro- and antiinflammatory mediators are likely important in regulating the signs and symptoms in dry eye.

\section{Peripheral sensitization}

The above inflammatory environment, along with other stresses such as hyperosmolarity, ${ }^{61}$ can affect the function of nociceptors with alterations in ion channel activity (increased sodium and calcium currents at the nociceptor terminal) through changes in gene expression and transcription, as reviewed by Pergolizzi et $a l^{28}$ and Costigan et al. ${ }^{62}$ The resultant phenotypic change of reduced activation thresholds and increased excitability is termed peripheral sensitization (Figure 3).

Peripheral sensitization can be reversed after resolution of the inciting stress and normalization of ocular surface inflammation (Figure 2). As noted, a few molecules including resolvins and protectins have been found to promote active receptor-mediated resolution of inflammation. ${ }^{60}$ In fact, various animal and human studies have shown that omega 3 fatty acids (from which resolvins and protectins are derived) improved symptoms, signs, and inflammation associated with dry eye. ${ }^{63-67}$ This effect is likely mediated through the biosynthetic process of omega fatty acids to resolvins and protectins. For example, neuroprotectin D1 (a product of docosahexaenoic acid (DHA)) was found to be as effective as DHA itself in improving corneal sensitivity and tear production and decreasing neutrophil infiltration after experimental nerve injury. ${ }^{68}$ Similarly, resolvin E1 (a product of eicosapentaenoic acid (EPA)) protected the ocular surface from adverse environmental conditions in mice with decreased staining and maintenance of goblet cell density ${ }^{69}$ In the same model, resolvins decreased COX2 expression and inflammatory cells infiltrates. ${ }^{70}$ Resolvins also interacted with cytokines by blocking TNF- $\alpha$-mediated effects in salivary gland tissue. ${ }^{71}$ Importantly, the regulation of pro-resolving mediators appear to be influenced by neuronal functioning and may be reduced after neuronal injury and dysfunction associated with a reduction in Netrin-1 affecting resolvin D1 production. ${ }^{72}$
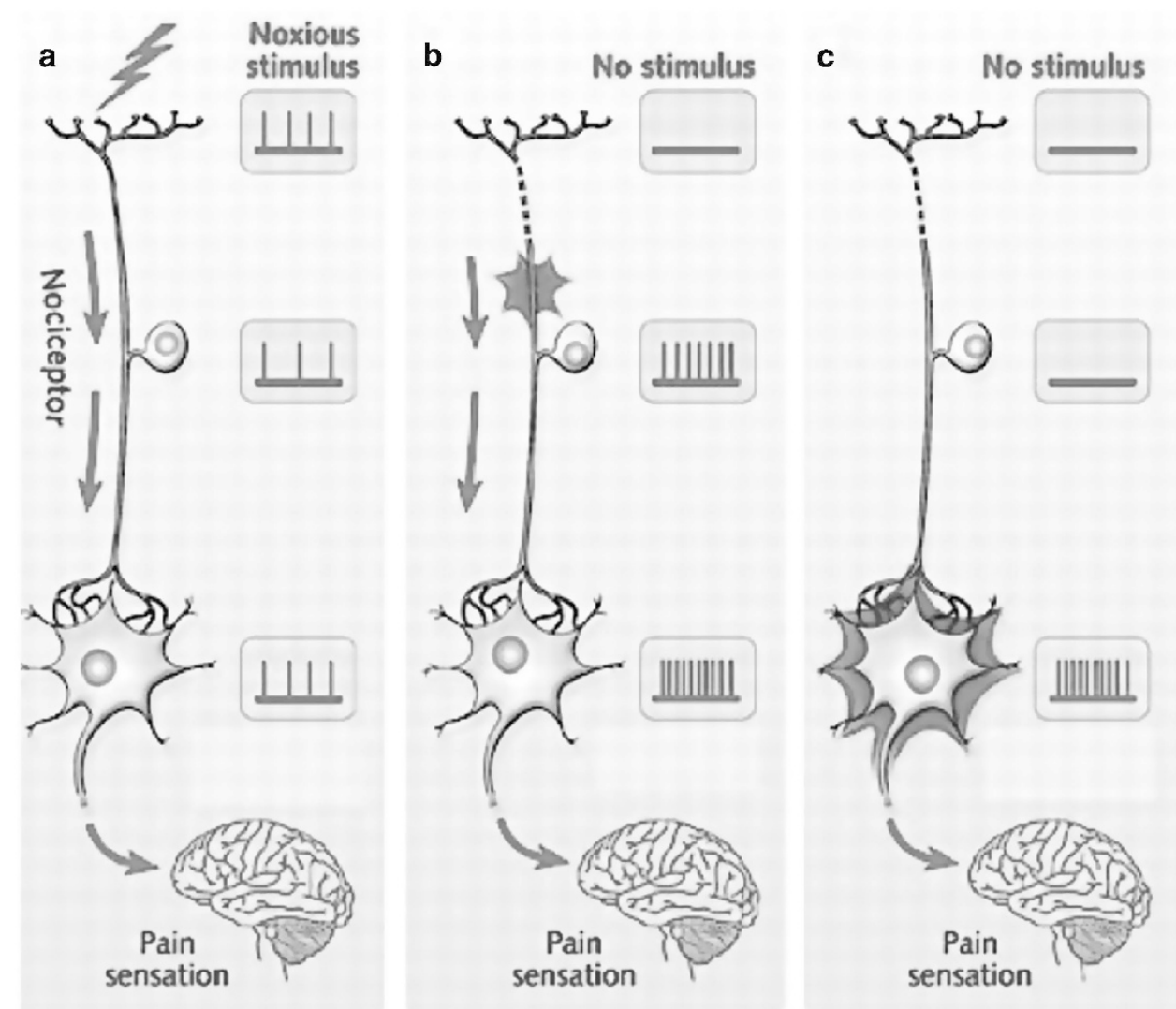

Figure 3 (a) Normal nociceptor response to a noxious stimulus is shown. (b) Neuroplasticity in the first-order neuron (peripheral sensitization). In the absence of a stimulus, the cell body and terminal end of the first-order neuron display spontaneous activity that translates into pain sensation. (c) Neuroplasticity in the second-order neuron (central sensitization). In the absence of a stimulus, the cell body of the second-order neuron displays spontaneous activity that translates into pain sensation. 


\section{Central sensitization and chronic dry eye symptoms}

If ocular surface damage persists, or if the inflammatory cascade is not dampened, changes may occur in the central nervous system (CNS) and produce central sensitization (Figure 3). This is defined as pain hypersensitivity that may arise from reduced activation thresholds and abnormal signaling amplification within the CNS. ${ }^{28}$ The hallmark of central sensitization is pain that is disconnected from ongoing peripheral pathology. This is commonly seen in dry eye as patient symptoms often do not mirror ocular surface findings. ${ }^{73}$ The process of central sensitization may also initially be reversible, but it often becomes permanent (Figure 4).

Although the mechanisms are not fully understood, central sensitization in nonocular pain conditions is frequently associated with the comorbidities depression and anxiety. ${ }^{74}$ A similar correlate has been described in dry eye as patients with depression and posttraumatic stress disorder (PTSD) were found to have a twofold increased risk of a dry eye diagnosis compared with patients without these diagnoses. ${ }^{75,76}$ Furthermore, evidence for a discordance between dry eye symptoms and peripheral pathology comes from findings that patients with PTSD and depression complained of more symptoms but had similar tear film parameters
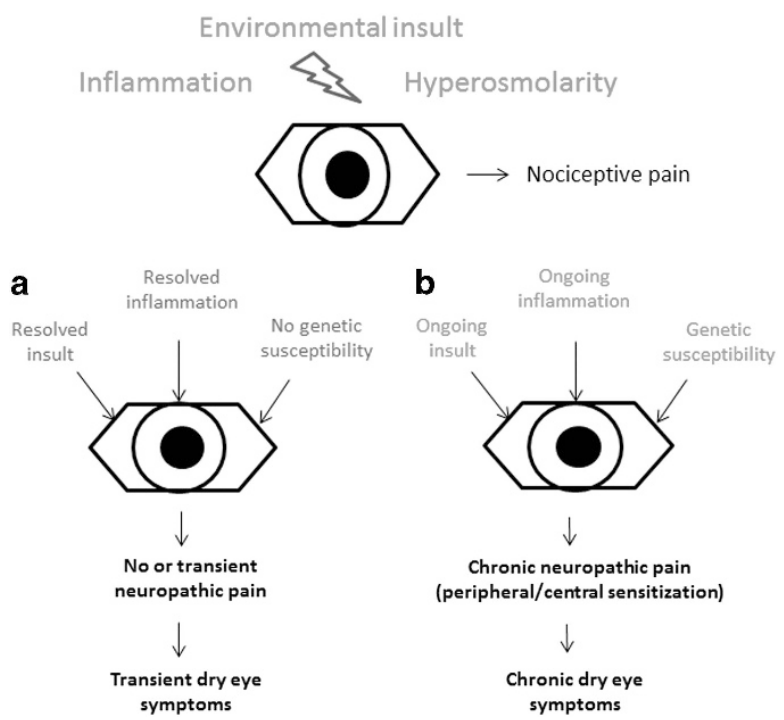

Figure 4 A simplified model of chronic dry eye development. Dry eye symptoms arise after an environmental insult, inflammation, and hyperosmolarity activate nociceptors (nociceptive pain). Typically, as in scenario a, the insult and inflammation resolve along with the dry eye symptoms. In susceptible patients, however, or in patients with ongoing insults, chronic changes can occur in the peripheral and central nervous system and lead to chronic dry eye symptoms (scenario b). Although the approach to patients in each category should differ, current dry eye measures do not incorporate ocular sensory apparatus function in their diagnosis or treatment algorithms. compared with patients without depression or PTSD. ${ }^{77}$ Others studies in Asian populations have described similar relationships between depression and dry eye. ${ }^{78-80}$

Hypersensitivity to other stimuli and the development of diffuse pain states can also be seen with central sensitization, ${ }^{74}$ and again these features have been described in dry eye. Data from the national VA database demonstrated that patients with chronic pain diagnoses (ICD-9 codes 338.29, 724.2, 724.5, 338.4, and 338.28) were 1.9 times more likely to carry a dry eye diagnosis compared with their counterparts without chronic pain (odds ratio (OR) 1.89, 95\% confidence interval (CI) 1.88 1.90). In addition, fibromyalgia (ICD-9 code 729.1) imparted a twofold increased risk for dry eye (OR 1.96, 95\% CI 1.94-1.98) whereas migraine (ICD-9 code 346) imparted a 1.4-fold increased risk (OR 1.37, 95\% CI 1.351.38) (A Galor et al, unpublished data). Additional support for the presence of central sensitization in some dry eye patients comes from a study of 1635 female twin volunteers in the United Kingdom. Patients with dry eye had higher pain sensitivity at a remote site (forearm) than those without the disease. ${ }^{81}$ These clinical data demonstrating abnormal functional responses to nonocular stimuli suggest heightened systemic pain sensitivity, consistent with central sensitization.

Similar to peripheral sensitization, changes in ion channel expression and function, levels of mediators, cytosolic signaling, and other factors underlie these phenotypic changes. ${ }^{62,82,83}$ As above, the anatomy of the ocular sensory apparatus lends biologic plausibility to the idea of central sensitization in dry eye. The first synapse of the ocular sensory apparatus occurs in the $\mathrm{Vi} / \mathrm{Vc}$ zone, and specific dry-responsive projection neurons have been identified in this area. A subset of these neurons receive additional converging input from corneal primary afferents sensitive to protons, heat, and chemicals. ${ }^{37}$ Therefore, projection neurons in the transition zone integrate innocuous as well as noxious sensory information from the eye, and may constitute the neurophysiological substrate of central sensitization. In fact, the Vi/Vc transition zone is a well-recognized area involved in the generation and maintenance of hyperexcitability and central sensitization. ${ }^{84}$

\section{Genetic predisposition may affect the dry eye phenotype by influencing ocular sensory apparatus function and/or the inflammatory cascade}

Genetic polymorphisms are well known to affect neuronal function and inflammation, and are therefore likely to modulate the clinical presentation of dry eye and affect its severity. Although there are only a few reports on genetic polymorphisms and symptoms of dry eye, substantial research supports the fact that relatively 
common inherited genetic polymorphisms underlie individual differences in pain perception, 85 pain-related behaviors, and the development of persistent pain syndromes. ${ }^{86,87}$ For example, COMT (catechol-O-methyl transferase) is an important gene whose functional variants have been described in over 100 publications and 30 reviews. COMT variants are associated with various forms of pain including neuropathic pain, musculoskeletal pain, fibromyalgia, temporomandibular disorder (TMD), headache, and postsurgical pain. ${ }^{88-93}$ Importantly, COMT alleles also predict pain severity. ${ }^{94}$ Furthermore, individuals homozygous for the COMT Val158Met variant consistently demonstrate psychological dysfunction associated with their chronic pain. ${ }^{95}$

Given the role of inflammation and dry eye, it is interesting that polymorphisms in the proinflammatory cytokine genes $I L-1 \beta$ (rs1143634) and $I L-6 R$ (rs8192284) were recently reported to be associated with nonSjogren's dry eye symptoms in a Korean population. ${ }^{96}$ This finding makes intuitive sense, as having a genetic propensity for inflammation can profoundly influence neuroplasticity and contribute to neuronal dysfunction and neuropathic pain. ${ }^{97-99}$ With only limited information available, more research is needed on genetic susceptibility to dry eye and the acute-to-chronic pain transition as well as epigenetic alterations that may be associated with the severity and persistence of symptoms.

\section{Neuropathic ocular pain and implications for dry eye diagnosis}

As above, neuropathic pain is more likely to be chronic, difficult to treat, and therefore important to distinguish in dry eye patients. Unfortunately, the presence of neuropathic ocular pain is not currently evaluated when assessing dry eye patients. This information is important as identifying patients with a neuropathic component to their dry eye symptoms may affect subsequent treatment. The easiest way to assess for neuropathic ocular pain is with the use of questionnaires. Although self-reported measures cannot definitely diagnose the presence of neuropathic pain, some clues can be obtained through a careful history. Unfortunately, most currently used dry eye questionnaires, such as the Ocular Surface Disease Index (OSDI) and Dry Eye Questionnaire 5 (DEQ5), 100 do not capture this important dimension of dry eye. For example, pain descriptors are often different in patients with neuropathic $v s$ nociceptive pain, with neuropathic pain often described as a burning, tingling, or electric pain. ${ }^{28}$ Asking patients to describe their corneal pain using well-established metrics ${ }^{101,102}$ may be a low-cost, first-line approach to identifying features of neuropathic pain in dry eye. Other features that suggest the presence of neuropathic pain include the presence of spontaneous pain and exaggerated pain response to normally nonnoxious stimuli (such as photoallodynia) and to suprathreshold noxious stimuli (such as hyperalgesia to wind).

Investigator-assessed features are more difficult to measure in dry eye as there are few commercially available instruments that can assess ocular sensory apparatus function in humans. Cochet-Bonnet aesthesiometery has been applied to dry eye and has demonstrated lower sensitivity to mechanical stimuli in dry eye patients. ${ }^{103,104}$ The Belmonte aesthesiometer, a more robust instrument that can measure sensitivity to mechanical (air flow), chemical $\left(\mathrm{CO}_{2}\right)$, and cooling stimuli, is unfortunately not commercially available. In those groups with such an instrument, most have found decreased sensitivity to all three stimuli in dry eye patients. ${ }^{105,106}$ However, some groups have found higher sensitivity to air flow in dry eye patients, 107,108 representing a different disease subtype or patients at different points on the disease continuum. Commercially available confocal microscopy units have identified that some dry eye patients have neuronal alterations in the corneal subbasal plexus structures. ${ }^{104,106,109,110}$ Dry eye patients, in general, have lower subbasal nerve density, ${ }^{104,106}$ and some also display abnormal nerve morphology including increased tortuosity and beading. ${ }^{110}$ Although not definitive, the findings of abnormal sensitivity and morphology in patients with chronic symptoms would suggest the presence of neuropathic pain.

\section{Neuropathic ocular pain and implications for dry eye treatment}

Understanding the neuropathology of dry eye will be important in developing alternative approaches to treating the disorder. The above data suggest that patients with evidence of neuropathic pain and central sensitization may be the patients who continue to have dry eye symptoms while on current therapies. In these patients, a multimodal approach may be more beneficial including treating ongoing ocular surface damage with ocular surface protection and anti-inflammatory agents, and ocular sensory apparatus dysfunction with antineuropathic pain treatment. Other untested therapies for dry eye include glial inhibitors, anti-inflammatory cytokines, and/or NMDA receptor inhibitors, all of which have been shown to attenuate facial painmediated via central mechanisms potentially common to those of dry eye. ${ }^{111-113}$ With many agents available to treat neuropathic pain, research is needed to understand 
the role, if any, of these agents in treating ocular sensory apparatus dysfunction associated with dry eye.

Systemically, there is still controversy on the best management algorithm for patients with neuropathic pain, and this may vary depending on pain severity, underlying pathophysiology (eg, postherpetic neuralgia (PHN), diabetic polyneuropathy), and systemic comorbidities. Our general algorithm for nonocular neuropathic pain includes the use of the novel alpha 2 delta ligand antiepileptics (eg, gabapentin; pregabalin) as first-line agents, serotonin-norepinephrine reuptake inhibitors (eg, duloxetine; venlafaxine) as second-line agents (or as first-line agents in certain patients, such as those with concomitant musculoskeletal pain or with concomitant depression), and tricyclic antidepressants (eg, nortriptyline, amitriptyline) as third-line agents because of their side effects. Combination therapies (antiepileptics and antidepressants) are also frequently used in cases where monotherapy provides only partial relief. In addition, depending on pain severity, opiods (eg, tramadol) can be used in selected patients, in conjunction with the therapies above. Topical agents (lidocaine and capsaicin) are also used even as first-line therapies or as parts of multimodal therapies or in specific conditions such as in the treatment of PHN. Short courses of corticosteroids or other anticonvulsants (topiramate, lamotrigine, carbamazepine, and so on) may be used in specific circumstances. More aggressive measures (eg, nerve blocks, spinal cord stimulation) are used in patients who have failed conservative therapy or if there are specific indications, such as for neuropathic pain localized in the area of innervation of a specific nerve and related to neuropathy of that nerve (eg, sympathetically maintained arm pain treated with stellate ganglion block). In addition, delivering all these therapies in a multidisciplinary approach is important. Therapies such as cognitive, behavioral, and physical therapy should be considered in most patients with chronic neuropathic pain.

Limited data are available to suggest whether a similar approach should be utilized in appropriately selected dry eye patients. One study that evaluated topical analgesics found that one drop of diclofenac decreased discomfort to high-intensity mechanical, chemical, and thermal stimuli (applied with the Belmonte aesthesiometer) in six healthy volunteers. Interestingly, in the same study, flurbiprofen was not found to have a similar effect. ${ }^{114}$ This differential effect may be because of the fact that diclofenac, in addition to its antiprostaglandin effects, also acts as a neuronal potassium (including $\mathrm{K}_{\text {ATP }}$ ) channel opener. ${ }^{115,116}$ Activation of neuronal potassium currents suppresses primary afferent neuronal excitability and firing, and attenuates increased excitatory neurotransmitter release and synaptic transmission, thus resulting in an antiallodynic and antihyperalgesic effect. ${ }^{115,117,118}$

In a similar manner, gabapentin and pregabalin, modulators of both peripheral central neuronal activity, have been shown to decrease postoperative pain after photorefractive keratectomy in prospective, randomized, placebo-controlled studies. ${ }^{119,120}$ Furthermore, some current dry eye treatments, such as omega 3 and doxycycline (an MMP inhibitor), likely have a direct effect on nerve function along with secondary effects by improving the ocular surface environment. ${ }^{121-123}$ Further studies are needed to assess whether topical and/or centrally acting neuromodulators have a role in the treatment of dry eye patients with features of NOP.

\section{Conclusions}

Dry eye has gained recognition as a public health problem given its prevalence, morbidity, and cost implications. Although dry eye was initially thought to be a 'simple' disease of tear dysfunction, exciting new research has revealed that it is a complicated disorder with potentially complex neuropathologic mechanisms. In fact, what we currently refer to as dry eye likely represents a heterogenous group composed of different disease subtypes with various levels of ocular sensory apparatus dysfunction.

Indeed, it is likely that a subset of dry eye patients have neuropathic pain and central sensitization. These patients are likely to be more resistant to topical therapy directed at optimizing the ocular surface. Differentiating between the different subgroups within dry eye and evaluating for the presence of neuropathic ocular pain will be critical to individualizing the treatment of dry eye.

\section{Conflict of interest}

The authors declare no conflict of interest.

\section{Acknowledgements}

This paper was supported by the Department of Veterans Affairs, Veterans Health Administration, Office of Research and Development, Clinical Sciences Research and Development's Career Development Award CDA-2024-10S (to Dr Galor), NIH Center Core Grant P30EY014801, Research to Prevent Blindness Unrestricted Grant, Department of Defense (DOD- Grant no. W81XWH-09-1-0675), and NIH NIDCR R01 DE022903 (to Drs Levitt and Martin). In addition, we note that the contents of this study do not represent the views of the Department of Veterans Affairs or the US Government. 


\section{References}

1 The definition and classification of dry eye disease: report of the Definition and Classification Subcommittee of the International Dry Eye WorkShop (2007). Ocul Surf 2007; 5(2): 75-92.

2 Stern ME, Gao J, Siemasko KF, Beuerman RW, Pflugfelder SC. The role of the lacrimal functional unit in the pathophysiology of dry eye. Exp Eye Res 2004; 78(3): 409-416.

3 Begley CG, Chalmers RL, Mitchell GL, Nichols KK, Caffery B, Simpson T et al. Characterization of ocular surface symptoms from optometric practices in North America. Cornea 2001; 20(6): 610-618.

4 Schein OD, Munoz B, Tielsch JM, Bandeen-Roche K, West $\mathrm{S}$. Prevalence of dry eye among the elderly. Am J Ophthalmol 1997; 124(6): 723-728.

5 Moss SE, Klein R, Klein BE. Prevalence of and risk factors for dry eye syndrome. Arch Ophthalmol 2000; 118(9): 1264-1268.

6 Bandeen-Roche K, Munoz B, Tielsch JM, West SK, Schein OD. Self-reported assessment of dry eye in a population-based setting. Invest Ophthalmol Vis Sci 1997; 38(12): 2469-2475.

7 Munoz B, West SK, Rubin GS, Schein OD, Quigley HA, Bressler SB et al. Causes of blindness and visual impairment in a population of older Americans: the Salisbury Eye Evaluation Study. Arch Ophthalmol 2000; 118(6): 819-825.

8 Brewitt H, Sistani F. Dry eye disease: the scale of the problem. Surv Ophthalmol 2001; 45(Suppl 2): S199-S202.

9 McCarty CA, Bansal AK, Livingston PM, Stanislavsky YL, Taylor HR. The epidemiology of dry eye in Melbourne, Australia. Ophthalmology 1998; 105(6): 1114-1119.

10 Chia EM, Mitchell P, Rochtchina E, Lee AJ, Maroun R, Wang JJ. Prevalence and associations of dry eye syndrome in an older population: the Blue Mountains Eye Study. Clin Exp Ophthalmol 2003; 31(3): 229-232.

11 Hikichi T, Yoshida A, Fukui Y, Hamano T, Ri M, Araki K et al. Prevalence of dry eye in Japanese eye centers. Graefes Arch Clin Exp Ophthalmol 1995; 233(9): 555-558.

12 Uchino M, Schaumberg DA, Dogru M, Uchino Y, Fukagawa K, Shimmura S et al. Prevalence of dry eye disease among Japanese visual display terminal users. Ophthalmology 2008; 115(11): 1982-1988.

13 Uchino M, Dogru M, Uchino Y, Fukagawa K, Shimmura S, Takebayashi T et al. Japan Ministry of Health study on prevalence of dry eye disease among Japanese high school students. Am J Ophthalmol 2008; 146(6): 925-929 e922.

14 Shimmura S, Shimazaki J, Tsubota K. Results of a population-based questionnaire on the symptoms and lifestyles associated with dry eye. Cornea 1999; 18(4): 408-411.

15 Sahai A, Malik P. Dry eye: prevalence and attributable risk factors in a hospital-based population. Indian J Ophthalmol 2005; 53(2): 87-91.

16 Lekhanont K, Rojanaporn D, Chuck RS, Vongthongsri A. Prevalence of dry eye in Bangkok, Thailand. Cornea 2006; 25(10): 1162-1167.

17 Lee AJ, Lee J, Saw SM, Gazzard G, Koh D, Widjaja D et al. Prevalence and risk factors associated with dry eye symptoms: a population based study in Indonesia. Br J Ophthalmol 2002; 86(12): 1347-1351.
18 The epidemiology of dry eye disease: report of the Epidemiology Subcommittee of the International Dry Eye WorkShop (2007). Ocul Surf 2007; 5(2): 93-107.

$19 \mathrm{Yu}$ J, Asche CV, Fairchild CJ. The economic burden of dry eye disease in the United States: a decision tree analysis. Cornea 2011; 30(4): 379-387.

20 Galor A, Zheng DD, Arheart KL, Lam BL, Perez VL, McCollister KE et al. Dry eye medication use and expenditures: data from the medical expenditure panel survey 2001 to 2006. Cornea 2012; 31(12): 1403-1407.

21 Mertzanis P, Abetz L, Rajagopalan K, Espindle D, Chalmers R, Snyder $\mathrm{C}$ et al. The relative burden of dry eye in patients' lives: comparisons to a U.S. normative sample. Invest Ophthalmol Vis Sci 2005; 46(1): 46-50.

22 Pouyeh B, Viteri E, Feuer W, Lee DJ, Florez H, Fabian JA et al. Impact of ocular surface symptoms on quality of life in a United States veterans affairs population. Am J Ophthalmol 2012; 153(6): 1061-1066 e1063.

23 Rajagopalan K, Abetz L, Mertzanis P, Espindle D, Begley C, Chalmers $\mathrm{R}$ et al. Comparing the discriminative validity of two generic and one disease-specific health-related quality of life measures in a sample of patients with dry eye. Value Health 2005; 8(2): 168-174.

24 De Paiva CS, Corrales RM, Villarreal AL, Farley WJ, Li DQ, Stern ME et al. Corticosteroid and doxycycline suppress MMP-9 and inflammatory cytokine expression, MAPK activation in the corneal epithelium in experimental dry eye. Exp Eye Res 2006; 83(3): 526-535.

25 Rosenthal P, Baran I, Jacobs DS. Corneal pain without stain: is it real? Ocul Surf 2009; 7(1): 28-40

26 Rosenthal P, Borsook D. The corneal pain system. Part I: the missing piece of the dry eye puzzle. Ocul Surf 2012; 10(1): $2-14$.

27 Definition of pain. International Assocation for the Study of Pain website. http://www.iasp-pain.org/Education/ Content.aspx?ItemNumber=1698\#Pain. Accessed July 15.

28 Pergolizzi J, Ahlbeck K, Aldington D, Alon E, Coluzzi F, Dahan A et al. The development of chronic pain: physiological CHANGE necessitates a multidisciplinary approach to treatment. Curr Med Res Opin 2013; 29(9): 1127-1135.

29 Geber C, Baumgartner U, Schwab R, Muller H, Stoeter P, Dieterich $\mathrm{M}$ et al. Revised definition of neuropathic pain and its grading system: an open case series illustrating its use in clinical practice. Am J Med 2009; 122(10 Suppl): S3-S12.

30 Muller LJ, Marfurt CF, Kruse F, Tervo TM. Corneal nerves: structure, contents and function. Exp Eye Res 2003; 76(5): 521-542.

31 Guthoff RF, Wienss H, Hahnel C, Wree A. Epithelial innervation of human cornea: a three-dimensional study using confocal laser scanning fluorescence microscopy. Cornea 2005; 24(5): 608-613.

32 Belmonte C, Gallar J. Cold thermoreceptors, unexpected players in tear production and ocular dryness sensations. Invest Ophthalmol Vis Sci 2011; 52(6): 3888-3892.

33 Hirata H, Meng ID. Cold-sensitive corneal afferents respond to a variety of ocular stimuli central to tear production: implications for dry eye disease. Invest Ophthalmol Vis Sci 2010; 51(8): 3969-3976.

34 Stapleton F, Marfurt C, Golebiowski B, Rosenblatt M, Bereiter D, Begley $\mathrm{C}$ et al. The TFOS International Workshop on Contact Lens Discomfort: report of the subcommittee on neurobiology. Invest Ophthalmol Vis Sci 2013; 54(11): TFOS71-TFOS97. 
35 Parra A, Madrid R, Echevarria D, del Olmo S, Morenilla-Palao C, Acosta MC et al. Ocular surface wetness is regulated by TRPM8-dependent cold thermoreceptors of the cornea. Nat Med 2010; 16(12): 1396-1399.

36 Okamoto K, Bereiter DF, Tashiro A, Bereiter DA. Ocular surface-evoked Fos-like immunoreactivity is enhanced in trigeminal subnucleus caudalis by prior exposure to endotoxin. Neuroscience 2009; 159(2): 787-794.

37 Kurose M, Meng ID. Corneal dry-responsive neurons in the spinal trigeminal nucleus respond to innocuous cooling in the rat. J Neurophysiol 2013; 109(10): 2517-2522.

38 Tashiro A, Okamoto K, Chang Z, Bereiter DA. Behavioral and neurophysiological correlates of nociception in an animal model of photokeratitis. Neuroscience 2010; 169(1): $455-462$.

39 Hirata H, Okamoto K, Tashiro A, Bereiter DA. A novel class of neurons at the trigeminal subnucleus interpolaris/ caudalis transition region monitors ocular surface fluid status and modulates tear production. J Neurosci 2004; 24(17): 4224-4232.

40 Ousler GW, Gomes PJ, Welch D, Abelson MB. Methodologies for the study of ocular surface disease. Ocul Surf 2005; 3(3): 143-154.

41 Lopez-Miguel A, Teson M, Martin-Montanez V, Enriquez-de-Salamanca A, Stern ME, Calonge M et al. Dry eye exacerbation in patients exposed to desiccating stress under controlled environmental conditions. Am J Ophthalmol 2014; 157(4): 788-798 e782.

42 Teson M, Gonzalez-Garcia MJ, Lopez-Miguel A, Enriquez-de-Salamanca A, Martin-Montanez V, Benito M] et al. Influence of a controlled environment simulating an in-flight airplane cabin on dry eye disease. Invest Ophthalmol Vis Sci 2013; 54(3): 2093-2099.

43 Lu P, Chen X, Liu X, Yu L, Kang Y, Xie Q et al. Dry eye syndrome in elderly Tibetans at high altitude: a population-based study in China. Cornea 2008; 27(5): 545-551.

44 Versura P, Profazio V, Cellini M, Torreggiani A, Caramazza R. Eye discomfort and air pollution. Ophthalmologica 1999; 213(2): 103-109.

45 Longo BM. The Kilauea Volcano adult health study. Nurs Res 2009; 58(1): 23-31.

46 Douwes J, McLean D, Slater T, Pearce N. Asthma and other respiratory symptoms in New Zealand pine processing sawmill workers. Am J Ind Med 2001; 39(6): 608-615.

47 Zuskin E, Mustajbegovic J, Schachter EN, Kern J, Doko-Jelinic J, Godnic-Cvar J. Respiratory findings in workers employed in the brick-manufacturing industry. J Occup Environ Med 1998; 40(9): 814-820.

48 Bulbulia A, Shaik R, Khan N, Vayej S, Kistnasamy B, Page T. Ocular health status of chemical industrial workers. Optom Vis Sci 1995; 72(4): 233-240.

49 Galor A, Kumar N, Feuer W, Lee DJ. Environmental factors affect the risk of dry eye syndrome in a United States veteran population. Ophthalmology 2014; 121(4): 972-973 e971.

50 Shim J, Park C, Lee HS, Park MS, Lim HT, Chauhan S et al. Change in prostaglandin expression levels and synthesizing activities in dry eye disease. Ophthalmology 2012; 119(11): 2211-2219.

51 Stern ME, Gao J, Schwalb TA, Ngo M, Tieu DD, Chan CC et al. Conjunctival T-cell subpopulations in Sjogren's and non-Sjogren's patients with dry eye. Invest Ophthalmol Vis Sci 2002; 43(8): 2609-2614.
52 Lee SY, Han SJ, Nam SM, Yoon SC, Ahn JM, Kim TI et al. Analysis of tear cytokines and clinical correlations in sjogren syndrome dry eye patients and non-sjogren syndrome dry eye patients. Am J Ophthalmol 2013; 156(2): 247-253 e241.

53 Massingale ML, Li X, Vallabhajosyula M, Chen D, Wei Y, Asbell PA. Analysis of inflammatory cytokines in the tears of dry eye patients. Cornea 2009; 28(9): 1023-1027.

54 Wakamatsu TH, Dogru M, Matsumoto Y, Kojima T, Kaido M, Ibrahim OM et al. Evaluation of lipid oxidative stress status in Sjogren syndrome patients. Invest Ophthalmol Vis Sci 2013; 54(1): 201-210.

55 He J, Bazan HE. Omega-3 fatty acids in dry eye and corneal nerve regeneration after refractive surgery. Prostaglandins Leukot Essent Fatty Acids 2010; 82(4-6): 319-325.

56 Lambiase A, Micera A, Pellegrini G, Merlo D, Rama P, De Luca $\mathrm{M}$ et al. In vitro evidence of nerve growth factor effects on human conjunctival epithelial cell differentiation and mucin gene expression. Invest Ophthalmol Vis Sci 2009; 50(10): 4622-4630.

57 Lambiase A, Micera A, Sacchetti M, Cortes M, Mantelli F, Bonini S. Alterations of tear neuromediators in dry eye disease. Arch Ophthalmol 2011; 129(8): 981-986.

58 Chotikavanich S, de Paiva CS, Li de Q, Chen JJ, Bian F, Farley WJ et al. Production and activity of matrix metalloproteinase-9 on the ocular surface increase in dysfunctional tear syndrome. Invest Ophthalmol Vis Sci 2009; 50(7): 3203-3209.

59 Sambursky R, Davitt 3rd WF, Latkany R, Tauber S, Starr C, Friedberg $\mathrm{M}$ et al. Sensitivity and specificity of a pointof-care matrix metalloproteinase 9 immunoassay for diagnosing inflammation related to dry eye. JAMA Ophthalmol 2013; 131(1): 24-28.

60 Serhan CN, Petasis NA. Resolvins and protectins in inflammation resolution. Chem Rev 2011; 111(10): 5922-5943.

61 Parra A, Gonzalez-Gonzalez O, Gallar J, Belmonte C. Tear fluid hyperosmolality increases nerve impulse activity of cold thermoreceptor endings of the cornea. Pain 2014; 155(8): 1481-1491.

62 Costigan M, Scholz J, Woolf CJ. Neuropathic pain: a maladaptive response of the nervous system to damage. Annu Rev Neurosci 2009; 32: 1-32.

63 Bhargava R, Kumar P, Kumar M, Mehra N, Mishra A. A randomized controlled trial of omega-3 fatty acids in dry eye syndrome. Int J Ophthalmol 2013; 6(6): 811-816.

64 Brignole-Baudouin F, Baudouin C, Aragona P, Rolando M, Labetoulle M, Pisella PJ et al. A multicentre, doublemasked, randomized, controlled trial assessing the effect of oral supplementation of omega- 3 and omega- 6 fatty acids on a conjunctival inflammatory marker in dry eye patients. Acta Ophthalmol 2011; 89(7): e591-e597.

65 Cortina MS, Bazan HE. Docosahexaenoic acid, protectins and dry eye. Curr Opin Clin Nutr Metab Care 2011; 14(2): 132-137.

66 Cortina MS, He J, Li N, Bazan NG, Bazan HE. Neuroprotectin D1 synthesis and corneal nerve regeneration after experimental surgery and treatment with PEDF plus DHA. Invest Ophthalmol Vis Sci 2010; 51(2): 804-810.

67 Cortina MS, He J, Li N, Bazan NG, Bazan HE. Recovery of corneal sensitivity, calcitonin gene-related peptide-positive nerves, and increased wound healing induced by pigment epithelial-derived factor plus docosahexaenoic acid after experimental surgery. Arch Ophthalmol 2012; 130(1): 76-83. 
68 Cortina MS, He J, Russ T, Bazan NG, Bazan HE. Neuroprotectin D1 restores corneal nerve integrity and function after damage from experimental surgery. Invest Ophthalmol Vis Sci 2013; 54(6): 4109-4116.

69 de Paiva CS, Schwartz CE, Gjorstrup P, Pflugfelder SC. Resolvin E1 (RX-10001) reduces corneal epithelial barrier disruption and protects against goblet cell loss in a murine model of dry eye. Cornea 2012; 31(11): 1299-1303.

70 Li N, He J, Schwartz CE, Gjorstrup P, Bazan HE. Resolvin E1 improves tear production and decreases inflammation in a dry eye mouse model. J Ocul Pharmacol Ther 2010; 26(5): 431-439.

71 Nelson JW, Leigh NJ, Mellas RE, McCall AD, Aguirre A, Baker OJ. ALX/FPR2 receptor for RvD1 is expressed and functional in salivary glands. Am J Physiol Cell Physiol 2014 306(2): C178-C185.

72 Mirakaj V, Dalli J, Granja T, Rosenberger P, Serhan CN. Vagus nerve controls resolution and pro-resolving mediators of inflammation. J Exp Med 2014; 211(6): 1037-1048.

73 Galor A, Feuer W, Lee DJ, Florez H, Venincasa VD, Perez VL. Ocular surface parameters in older male veterans. Invest Ophthalmol Vis Sci 2013; 54(2): 1426-1433.

74 Smart KM, Blake C, Staines A, Doody C. Self-reported pain severity, quality of life, disability, anxiety and depression in patients classified with 'nociceptive', 'peripheral neuropathic' and 'central sensitisation' pain. The discriminant validity of mechanisms-based classifications of low back (+/-leg) pain. Man Ther 2012; 17(2): 119-125

75 Galor A, Feuer W, Lee DJ, Florez H, Carter D, Pouyeh B et al. Prevalence and risk factors of dry eye syndrome in a United States veterans affairs population. Am J Ophthalmol 2011; 152(3): 377-384 e372.

76 Galor A, Feuer W, Lee DJ, Florez H, Faler AL, Zann KL et al. Depression, post-traumatic stress disorder, and dry eye syndrome: a study utilizing the national United States Veterans Affairs administrative database. Am J Ophthalmol 2012; 154(2): 340-346 e342.

77 Fernandez CA, Galor A, Arheart KL, Musselman DL, Venincasa VD, Florez HJ et al. Dry eye syndrome, posttraumatic stress disorder, and depression in an older male veteran population. Invest Ophthalmol Vis Sci 2013; 54(5): 3666-3672

78 Labbe A, Wang YX, Jie Y, Baudouin C, Jonas JB, Xu L. Dry eye disease, dry eye symptoms and depression: the Beijing Eye Study. Br J Ophthalmol 2013; 97(11): 1399-1403.

79 Wen W, Wu Y, Chen Y, Gong L, Li M, Chen X et al. Dry eye disease in patients with depressive and anxiety disorders in Shanghai. Cornea 2012; 31(6): 686-692.

80 Kim KW, Han SB, Han ER, Woo SJ, Lee JJ, Yoon JC et al. Association between depression and dry eye disease in an elderly population. Invest Ophthalmol Vis Sci 2011; 52(11): 7954-7958

81 Vehof J, Kozareva D, Hysi PG, Harris J, Nessa A, Williams FK et al. Relationship between dry eye symptoms and pain sensitivity. JAMA Ophthalmol 2013; 131(10): 1304-1308.

82 Woolf CJ. Dissecting out mechanisms responsible for peripheral neuropathic pain: implications for diagnosis and therapy. Life Sci 2004; 74(21): 2605-2610.

83 Waxman SG, Zamponi GW. Regulating excitability of peripheral afferents: emerging ion channel targets. Nat Neurosci 2014; 17(2): 153-163.

84 Sarantopoulos C. Burning mouth syndrome: a misunderstood, underinvestigated, and undertreated clinical challenge. Reg Anesth Pain Med 2013; 38(5): 378-379.
85 Diatchenko L, Nackley AG, Tchivileva IE, Shabalina SA, Maixner W. Genetic architecture of human pain perception. Trends Genet 2007; 23(12): 605-613.

86 Costigan M, Belfer I, Griffin RS, Dai F, Barrett LB, Coppola G et al. Multiple chronic pain states are associated with a common amino acid-changing allele in KCNS1. Brain 2010; 133(9): 2519-2527.

87 Katz J, Seltzer Z. Transition from acute to chronic postsurgical pain: risk factors and protective factors. Expert Rev Neurother 2009; 9(5): 723-744.

88 Diatchenko L, Nackley AG, Slade GD, Bhalang K, Belfer I, Max MB et al. Catechol-O-methyltransferase gene polymorphisms are associated with multiple pain-evoking stimuli. Pain 2006; 125(3): 216-224.

89 McLean SA, Diatchenko L, Lee YM, Swor RA, Domeier RM, Jones JS et al. Catechol O-methyltransferase haplotype predicts immediate musculoskeletal neck pain and psychological symptoms after motor vehicle collision. I Pain 2011; 12(1): 101-107.

90 Erdal ME, Herken H, Yilmaz M, Bayazit YA. Association of the T102C polymorphism of 5-HT2A receptor gene with aura in migraine. I Neurol Sci 2001; 188(1-2): 99-101.

91 Kim H, Mittal DP, Iadarola MJ, Dionne RA. Genetic predictors for acute experimental cold and heat pain sensitivity in humans. J Med Genet 2006; 43(8): e40.

92 Dai F, Belfer I, Schwartz CE, Banco R, Martha JF, Tighioughart $\mathrm{H}$ et al. Association of catechol-Omethyltransferase genetic variants with outcome in patients undergoing surgical treatment for lumbar degenerative disc disease. Spine I 2010; 10(11): 949-957.

93 Armero P, Muriel C, Santos J, Sanchez-Montero FJ, Rodriguez RE, Gonzalez-Sarmiento R. COMT (Val158Met) polymorphism is not associated to neuropathic pain in a Spanish population. Eur J Pain 2005; 9(3): 229-232.

94 Orrey DC, Bortsov AV, Hoskins JM, Shupp JW, Jones SW, Cicuto BJ et al. Catechol-O-methyltransferase genotype predicts pain severity in hospitalized burn patients. I Burn Care Res 2012; 33(4): 518-523.

95 Desmeules J, Piguet V, Besson M, Chabert J, Rapiti E, Rebsamen $\mathrm{M}$ et al. Psychological distress in fibromyalgia patients: a role for catechol-O-methyl-transferase Val158met polymorphism. Health Psychol 2012; 31(2): 242-249.

96 Na KS, Mok JW, Kim JY, Joo CK. Proinflammatory gene polymorphisms are potentially associated with Korean non-Sjogren dry eye patients. Mol Vis 2011; 17: 2818-2823.

97 Ren K, Dubner R. Neuron-glia crosstalk gets serious: role in pain hypersensitivity. Curr Opin Anaesthesiol 2008; 21(5): 570-579.

98 Kawasaki Y, Zhang L, Cheng JK, Ji RR. Cytokine mechanisms of central sensitization: distinct and overlapping role of interleukin-1beta, interleukin-6, and tumor necrosis factor-alpha in regulating synaptic and neuronal activity in the superficial spinal cord. J Neurosci 2008; 28(20): 5189-5194.

99 Rutkowski MD, DeLeo JA. The role of cytokines in the initiation and maintenance of chronic pain. Drug News Perspect 2002; 15(10): 626-632.

100 Chalmers RL, Begley CG, Caffery B. Validation of the 5-item dry eye questionnaire (DEQ-5): discrimination across self-assessed severity and aqueous tear deficient dry eye diagnoses. Cont Lens Ant Eye 2010; 33(2): 55-60.

101 Lovejoy TI, Turk DC, Morasco BJ. Evaluation of the psychometric properties of the revised short-form McGill Pain Questionnaire. J Pain 2012; 13(12): 1250-1257. 
102 Bouhassira D, Attal N, Fermanian J, Alchaar H, Gautron M, Masquelier E et al. Development and validation of the Neuropathic Pain Symptom Inventory. Pain 2004; 108(3): 248-257.

103 Hosal BM, Ornek N, Zilelioglu G, Elhan AH. Morphology of corneal nerves and corneal sensation in dry eye: a preliminary study. Eye 2005; 19(12): 1276-1279.

104 Labbe A, Alalwani H, Van Went C, Brasnu E, Georgescu D, Baudouin $C$. The relationship between subbasal nerve morphology and corneal sensation in ocular surface disease. Invest Ophthalmol Vis Sci 2012; 53(8): 4926-4931.

105 Bourcier T, Acosta MC, Borderie V, Borras F, Gallar J, Bury $\mathrm{T}$ et al. Decreased corneal sensitivity in patients with dry eye. Invest Ophthalmol Vis Sci 2005; 46(7): 2341-2345.

106 Benitez-Del-Castillo JM, Acosta MC, Wassfi MA, Diaz-Valle D, Gegundez JA, Fernandez C et al. Relation between corneal innervation with confocal microscopy and corneal sensitivity with noncontact esthesiometry in patients with dry eye. Invest Ophthalmol Vis Sci 2007; 48(1): 173-181.

107 Situ P, Simpson TL, Fonn D, Jones LW. Conjunctival and corneal pneumatic sensitivity is associated with signs and symptoms of ocular dryness. Invest Ophthalmol Vis Sci 2008 49(7): 2971-2976.

108 De Paiva CS, Pflugfelder SC. Corneal epitheliopathy of dry eye induces hyperesthesia to mechanical air jet stimulation. Am J Ophthalmol 2004; 137(1): 109-115.

109 Benitez del Castillo JM, Wasfy MA, Fernandez C, Garcia-Sanchez J. An in vivo confocal masked study on corneal epithelium and subbasal nerves in patients with dry eye. Invest Ophthalmol Vis Sci 2004; 45(9): 3030-3035.

110 Labbe A, Liang Q, Wang Z, Zhang Y, Xu L, Baudouin C et al Corneal nerve structure and function in patients with non-sjogren dry eye: clinical correlations. Invest Ophthalmol Vis Sci 2013; 54(8): 5144-5150.

111 Shimizu K, Guo W, Wang H, Zou S, LaGraize SC, Iwata K et al. Differential involvement of trigeminal transition zone and laminated subnucleus caudalis in orofacial deep and cutaneous hyperalgesia: the effects of interleukin-10 and glial inhibitors. Mol Pain 2009; 5: 75.

112 Guo W, Wang H, Watanabe M, Shimizu K, Zou S, LaGraize SC et al. Glial-cytokine-neuronal interactions underlying the mechanisms of persistent pain. J Neurosci 2007; 27(22): 6006-6018.

113 Ren K, Dubner R. The role of trigeminal interpolariscaudalis transition zone in persistent orofacial pain. Int Rev Neurobiol 2011; 97: 207-225.
114 Acosta MC, Berenguer-Ruiz L, Garcia-Galvez A, Perea-Tortosa D, Gallar J, Belmonte C. Changes in mechanical, chemical, and thermal sensitivity of the cornea after topical application of nonsteroidal antiinflammatory drugs. Invest Ophthalmol Vis Sci 2005; 46(1): 282-286.

115 Huang CW, Hung TY, Liao YK, Hsu MC, Wu SN. Underlying mechanism of regulatory actions of diclofenac, a nonsteroidal anti-inflammatory agent, on neuronal potassium channels and firing: an experimental and theorethical study. I Physiol Pharmacol 2013; 64(3): 269-280.

116 Ortiz MI, Castaneda-Hernandez G, Izquierdo-Vega JA, Sanchez-Gutierrez M, Ponce-Monter HA, Granados-Soto V. Role of ATP-sensitive $\mathrm{K}+$ channels in the antinociception induced by non-steroidal anti-inflammatory drugs in streptozotocin-diabetic and non-diabetic rats. Pharmacol Biochem Behav 2012; 102(1): 163-169.

117 Kawano T, Zoga V, Gemes G, McCallum JB, Wu HE, Pravdic D et al. Suppressed Ca2 + /CaM/CaMKIIdependent K(ATP) channel activity in primary afferent neurons mediates hyperalgesia after axotomy. Proc Natl Acad Sci USA 2009; 106(21): 8725-8730.

118 Kawano T, Zoga V, McCallum JB, Wu HE, Gemes G, Liang MY et al. ATP-sensitive potassium currents in rat primary afferent neurons: biophysical, pharmacological properties, and alterations by painful nerve injury. Neuroscience 2009; 162(2): 431-443.

119 Pakravan M, Roshani M, Yazdani S, Faramazi A, Yaseri M. Pregabalin and gabapentin for post-photorefractive keratectomy pain: a randomized controlled trial. Eur J Ophthalmol 2012; 22(Suppl 7): S106-S113.

120 Lichtinger A, Purcell TL, Schanzlin DJ, Chayet AS. Gabapentin for postoperative pain after photorefractive keratectomy: a prospective, randomized, double-blind, placebo-controlled trial. J Refract Surg 2011; 27(8): 613-617.

121 Figueroa JD, Cordero K, Serrano-Illan M, Almeyda A, Baldeosingh $\mathrm{K}$, Almaguel FG et al. Metabolomics uncovers dietary omega-3 fatty acid-derived metabolites implicated in anti-nociceptive responses after experimental spinal cord injury. Neuroscience 2013; 255: 1-18.

122 Ko GD, Nowacki NB, Arseneau L, Eitel M, Hum A. Omega-3 fatty acids for neuropathic pain: case series. Clin J Pain 2010; 26(2): 168-172.

123 Ji RR, Xu ZZ, Wang X, Lo EH. Matrix metalloprotease regulation of neuropathic pain. Trends Pharmacol Sci 2009; 30(7): 336-340. 